\title{
Evaluation of Trace Element Levels and Antioxidant Metabolism in Cattle with Cutaneous Papillomatosis
}

\author{
Handan Hilal Arslan', Duygu Tarhan'2, Sena Cenesiz ${ }^{3}$, Fatma Ates Alkan², \\ Umit Ozcan', Esma Tongut Arslan ${ }^{4}$, Umit Bora Barutcu² \& Mehmet Erman Or ${ }^{5}$
}

\begin{abstract}
Background: Cutaneous papillomas are benign proliferative neoplasms. The aetiology and pathogenesis of the disease are very complex. Papillomatosis lesions can be detected anywhere on the body, frequently appearing on the surface of the head, neck, teats, udder, external genital mucosa and upper part of the gastrointestinal tract. The disease is not life threatening but due to loss of productivity, owners often cull animals with papillomatosis. The relationships between trace elements, heavy metals and cancer are still researching. The aim of this study was the evaluation of the relationships between trace elements and antioxidant metabolism, and cutaneous papillomatosis, in cattle.
\end{abstract}

Materials, Methods \& Results: Eleven cattle with cutaneous papillomatosis and 10 healthy cattle constituted the study group and control group, respectively. Clinical examinations were performed on all animals. Blood samples were collected and $\mathrm{Cr}, \mathrm{Cu}, \mathrm{Fe}, \mathrm{Mg}, \mathrm{Mn}, \mathrm{Se}, \mathrm{Zn}, \mathrm{As}, \mathrm{B}, \mathrm{Ni}, \mathrm{Si}$ and Co levels were determined. The analyses were conducted with an inductively coupled plasma-optical emission spectrophotometer. In addition, catalase (CAT), glutathione (GSH), malondialdehyde (MDA) and ceruloplasmin (Cp) concentrations were measured. The $\mathrm{Ni}, \mathrm{Si}$ and MDA levels of the study group were significantly higher than those of the control group $(P<0.05)$ but the Se levels of the study group were significantly lower than in the control group $(P<0.05)$. The normality of the data was determined with the Shapiro-Wilk Test and the Independent Samples $t$-Test or Mann-Whitney U test was used for statistical comparison of the groups.

Discussion: Trace elements are essential components of biological systems. The levels of trace elements, such as $\mathrm{Cu}$, $\mathrm{Co}, \mathrm{I}, \mathrm{Se}, \mathrm{Zn}$ and $\mathrm{Mn}$, which are affected by grazing activity, influence ruminants' reproductive performance and other production parameters. The elements $\mathrm{Al}, \mathrm{As}, \mathrm{Cr}, \mathrm{Ni}$ and $\mathrm{Sn}$ are also presumed to be essential for ruminant metabolism, although sufficient research data are not available. In the present study, $\mathrm{Cr}, \mathrm{Cu}, \mathrm{Fe}, \mathrm{Mg}, \mathrm{Mn}, \mathrm{Zn}, \mathrm{As}, \mathrm{B}$ and Co levels were not significantly different between the papilloma and control groups. Se is an important trace element for skin health. This study revealed a mean serum Se level in animals with papillomatosis that was significantly lower than in the healthy group. Although the mode of anticancer activity of Se is not clear, some factors, such as antioxidant protection, improved immune system surveillance, carcinogen detoxification, modulation of cell proliferation and inhibition of tumour cell invasion and angiogenesis, are important. $\mathrm{Ni}$ is classified as a toxic heavy metal. In addition, it could be carcinogenic to humans. Ni level was two times higher in the papillomatosis group than in the healthy animals, in the present study. This result may indicate that $\mathrm{Ni}$ has a role in the genesis of papillomatosis in cattle. Si injection can cause inflammation, granulomas and cancer. There are few reports about Si levels in animals and the significant difference in the Si levels in cattle with cutaneous papillomatosis reported in this study may be a new indicator for the disease. The skin contains antioxidant molecules that include GSH, alpha-tocopherol or vitamin E, ascorbic acid or vitamin C, glutathione peroxidases, glutathione reductase, glutathione S-transferases (GSTs), superoxide dismutases (SODs), CAT and quinine reductase. There is strong interaction between ROS and/or their oxidant products and antioxidant molecules in the skin. In this study, although MDA levels were higher in the study group than in the control group, there was no significant difference between the groups in their CAT levels, and also in the GSH and CP levels. In conclusion, these results may evidence the systemic effects of papillomatosis on trace element levels and on oxidant metabolism in cattle.

Keywords: papillomatosis, cattle, trace elements, antioxidant metabolism.

DOI: $10.22456 / 1679-9216.82553$

${ }^{1}$ Department of Internal Medicine, Faculty of Veterinary Medicine, Ondokuz Mayis University, Samsun, Turkey. ${ }^{2}$ Department of Biophysics, Cerrahpasa Faculty of Medicine, Istanbul University, Istanbul, Turkey. ${ }^{3}$ Department of Biochemistry, Faculty of Veterinary Medicine, Ondokuz Mayis University, Samsun. ${ }^{4}$ DVM, Corum, Turkey. ${ }^{5}$ Department of Internal Medicine, Faculty of Veterinary Medicine, Istanbul University, Istanbul, Turkey. CORRESPONDENCE: H.H. Arslan [hharslan@ omu.edu.tr - Fax: +90 (362) 4576922]. Department of Internal Medicine, Faculty of Veterinary Medicine, Ondokuz Mayis University. 55139 Samsun, Turkey. 


\section{INTRODUCTION}

Cutaneous papillomas are benign proliferative neoplasms. The aetiology and pathogenesis of the disease are very complex. Some types of skin papillomas are caused by papilloma virus in other than bovines; for example dogs, cats, horses, donkeys, reptiles, some rodent species and humans [10,22]. Most papillomas are benign and do not lead to cancer [22]. The disease is usually detected in young cattle [12].

Papillomatosis lesions can be detected anywhere on the body, frequently appearing on the surface of the head, neck, teats, udder, external genital mucosa and upper part of the gastrointestinal tract. The disease is not life threatening but udder lesions can be an important problem for dairy cattle, including the suckling of calves [10]. In addition, due to loss of productivity, owners often cull animals with papillomatosis. The relationships between trace elements, heavy metals and cancer have been intensively researched. For example, selenium (Se) appears to reduce the risk of cancer and have a protective effect but cadmium (Cd), nickel (Ni) and arsenic (As) increase the risk of developing many cancers [16,21].

Reactive oxygen species (ROS) are a family of oxygen-based, free radicals [24]. Oxidative stress refers to an imbalance due to excess ROS or oxidants over the capacity of antioxidant system cells [20]. In the presence of this oxidant accumulation, lipid peroxidation occurs and subsequently pathological changes in cell and tissue function occur. Oxidative stress induces skin carcinogenesis [24].

The aim of this study was the evaluation of the relationships between trace elements and antioxidant metabolism, and cutaneous papillomatosis, in cattle.

\section{MATERIALS AND METHODS}

\section{Animals}

A total of 21 cattle from the same village in Corum, Turkey were used in the study. Eleven of the cattle had been diagnosed with cutaneous papilloma and they were used as the study group. The remaining 10 cattle, which were healthy, were used as the control group.

\section{Clinical examination}

All the cattle were clinically examined. In addition, blood samples were collected from the jugular vein of all cattle into sterile, empty tubes for biochemical analyses and tubes containing EDTA for the determination of the levels of a number of trace elements, namely chrome $(\mathrm{Cr})$, copper $(\mathrm{Cu})$, iron $(\mathrm{Fe})$, magnesium $(\mathrm{Mg})$, manganese $(\mathrm{Mn}), \mathrm{Se}, \mathrm{Zn}, \mathrm{As}$, boron (B), Ni, silicon ( $\mathrm{Si}$ ) and cobalt (Co). In addition, the blood samples were analysed to determine their catalase (CAT), glutathione (GSH), malondialdehyde (MDA) and ceruloplasmin (Cp) concentrations.

\section{Biochemical analyses}

MDA levels were determined on the basis of thiobarbuturic acid reactivity [26]. Determination of GSH concentration was carried out according to the method of Beutler et al. [5], CAT activity was determined according to Aebi's method [1], and the serum Cp level was determined spectrophotometrically (GenesysTM 10S UV-Vis Spectrophotometer) ${ }^{1}$ by using the method of Ravin [19].

\section{Trace element analyses}

Serum samples obtained from the study were stored at $-80^{\circ} \mathrm{C}$ until the analysis. They were prepared for trace element measurements by diluting 1:10 with distilled water. The analyses were conducted with an inductively coupled plasma-optical emission spectrophotometer (ICP-OES Thermo iCAP 6000 series) ${ }^{1}$ at the Trace Element Analysis Laboratory of the Biophysics Department of Cerrahpasa Faculty of Medicine in Istanbul, Turkey. The wave lengths, 267.716, 324.754, 259.940, 285.213, 257.610, 196.090, 206.200, 189.042, 249.773, 221.647, 251.611 and $228.616 \mathrm{~nm}$, were used for the determinations of $\mathrm{Cr}, \mathrm{Cu}, \mathrm{Fe}, \mathrm{Mg}$, $\mathrm{Mn}, \mathrm{Se}, \mathrm{Zn}, \mathrm{As}, \mathrm{B}, \mathrm{Ni}, \mathrm{Si}$ and Co levels, respectively, in the ICP-OES device. Stock solutions were prepared from standard solutions (Chem-Lab NV) containing $\mathrm{Cu}, \mathrm{Mg}, \mathrm{Se}, \mathrm{Zn}, \mathrm{Mn}$ As, B, Fe, Ni, Si Cr and Co. Distilled water was used as the blank solution. Each calibration curves were obtained from the ICP-OES device by using blank and standard solutions and the concentrations of the elements in the prepared serum samples. Results are expressed in milligrams per litre $[\mathrm{ppm}=\mathrm{mg} / \mathrm{L}]$.

\section{Statistical analyses}

The normality of the data was determined with the Shapiro-Wilk Test and the Independent Samples $t$-Test or Mann-Whitney U test was used for statistical comparison of the groups. Means are presented with standard deviations. Differences were considered significant when $P$ values were less than $0.05(P<0.05)$. 


\section{RESULTS}

In the cattle serum, $\mathrm{Se}, \mathrm{Ni}$ and $\mathrm{Si}$ levels of the cutaneous papillomatosis group were significantly different from the control group (Table 1).

Table 1. Trace element levels of the groups (Mean \pm SD).

\begin{tabular}{ccc}
\hline Parameter & Control $(\mathrm{n}=10)$ & Study $(\mathrm{n}=11)$ \\
\hline $\mathrm{Cr}$ & $0.01 \pm 0.005$ & $0.01 \pm 0.009$ \\
$\mathrm{Cu}$ & $0.45 \pm 0.09$ & $0.45 \pm 0.07$ \\
$\mathrm{Fe}$ & $1.16 \pm 0.48$ & $1.48 \pm 0.57$ \\
$\mathrm{Mg}$ & $16.64 \pm 1.67$ & $18.07 \pm 1.57$ \\
$\mathrm{Mn}$ & $0.001 \pm 0.0004$ & $0.001 \pm 0.0003$ \\
$\mathrm{Se}$ & $0.27 \pm 0.04$ & $0.22 \pm 0.06^{*}$ \\
$\mathrm{Zn}$ & $0.51 \pm 0.01$ & $0.44 \pm 0.22$ \\
$\mathrm{As}$ & $0.29 \pm 0.05$ & $0.29 \pm 0.04$ \\
$\mathrm{~B}$ & $0.16 \pm 0.05$ & $0.21 \pm 0.08$ \\
$\mathrm{Ni}$ & $0.01 \pm 0.003$ & $0.02 \pm 0.003^{*}$ \\
$\mathrm{Si}$ & $1.13 \pm 0.22$ & $1.65 \pm 0.52^{*}$ \\
$\mathrm{Co}$ & $0.003 \pm 0.003$ & $0.003 \pm 0.003$ \\
\hline
\end{tabular}

*Significantly different from the control group $(P<0.05)$.

In addition, the $\mathrm{Cp}$, MDA, CAT and GSH levels were assessed to evaluate antioxidant metabolism status (Table 2). Only the MDA level of the study group was significantly higher than that of the control group $(P<0.05)$.

Table 2. Oxidative stress parameters of the groups (Mean $\pm \mathrm{SD}$ ).

\begin{tabular}{ccc}
\hline Parameter & Control $(\mathrm{n}=10)$ & Study $(\mathrm{n}=11)$ \\
\hline Cp & $18.20 \pm 4.29$ & $16.91 \pm 3.14$ \\
MDA & $6.50 \pm 3.63$ & $17.23 \pm 2.80^{*}$ \\
CAT & $16.68 \pm 6.43$ & $28.96 \pm 27.05$ \\
GSH & $27.20 \pm 24.56$ & $25.82 \pm 13.96$ \\
\hline
\end{tabular}

*Significantly different from the control group $(P<0.05)$.

\section{DISCUSSION}

Trace elements are essential components of biological systems. Their effects are related to their concentrations. The concentration of trace elements in the body can range from deficiency to excess, and depending on the concentration, disturbance of the organism's metabolism can occur. Excessive accumulation can also disturb the functioning of other trace elements [23].

The levels of trace elements, such as $\mathrm{Cu}, \mathrm{Co}$, I, $\mathrm{Se}, \mathrm{Zn}$ and $\mathrm{Mn}$, which are affected by grazing activity, influence ruminants' reproductive performance and other production parameters [8]. The elements Al, As,
$\mathrm{Cr}, \mathrm{Ni}$ and $\mathrm{Sn}$ are also presumed to be essential for ruminant metabolism, although research data are not available [14]. In the present study, $\mathrm{Cr}, \mathrm{Cu}, \mathrm{Fe}, \mathrm{Mg}$, $\mathrm{Mn}, \mathrm{Zn}, \mathrm{As}, \mathrm{B}$ and Co levels were not significantly different between the papilloma and control groups. Se is an important trace element for skin health. In recent decades, research has focused on the relationship between Se and skin cancer, with varying reports about the protective effects of Se [11] e.g. experimental studies indicated that Se supplementation reduces the incidence of cancer in animals [21]. Therefore, the Se level was investigated in this study to better understand the possible relationship between cutaneous papillomatosis and the Se level.

This study revealed a mean serum Se level in animals with papillomatosis that was significantly lower than in the healthy group. This result corroborates the result of Willett et al. [25] who reported that the mean Se level in cancer cases in human was significantly lower than that of the controls. Se bonds to protein but it is also taken up by tumour cells which explains why the Se level decreases in the blood in skin cancer cases [23]. Decreased levels of Se may increase susceptibility to cancer, in cases of exposure to carcinogens or a reduction in the body's ability to withstand cancer-inducing stress [2]. Although the mode of anticancer activity of Se is not clear, some factors, such as antioxidant protection, improved immune system surveillance, carcinogen detoxification, modulation of cell proliferation and inhibition of tumour cell invasion and angiogenesis, are important [27].

$\mathrm{Ni}$ is classified as a toxic heavy metal [4]. Metallic Ni, Ni monoxides, Ni hydroxides and crystalline $\mathrm{Ni}$ sulphides have been reported to be carcinogenic in experimental animals. In addition, Ni could be carcinogenic to humans and it could be one reason for increased risk of lung and nasal cancer [7]. Therefore, the serum Ni level was determined in cattle with papillomatosis. That determination showed a Ni level two times higher in the papillomatosis group than in the healthy animals. This result may indicate that $\mathrm{Ni}$ has a role in the genesis of papillomatosis in cattle.

There are also some indications that Si might be important in some forms of infection and inflammation [17]. In human medicine, $\mathrm{Si}$ is employed in cosmetic surgery. However, there is evidence that $\mathrm{Si}$ injection can cause inflammation, granulomas and cancer [15]. There are few reports about Si levels in 
animals and the significant difference in the Si levels in cattle with cutaneous papillomatosis reported in this study may be a new indicator for the disease.

The skin is a vital organ that protects the internal organs from a multitude of environmental threats. ROS defence mechanisms are involved in the development of cutaneous diseases and disorders [24]. The role of ROS in cancer has been intensively investigated for the last 50 years and is firmly established. It is clear that low levels of ROS are beneficial for the organism. However, excess accumulation of these chemicals can be a factor in cancer formation [18].

The skin contains antioxidant molecules that include GSH, alpha-tocopherol or vitamin E, ascorbic acid or vitamin $\mathrm{C}$, glutathione peroxidases, glutathione reductase, glutathione S-transferases (GSTs), superoxide dismutases (SODs), CAT and quinine reductase. There is strong interaction between ROS and/or their oxidant products and antioxidant molecules in the skin [6]. In the present study, although CAT levels were higher in the study group than in the control group, there was no significant difference between the groups in their CAT levels, and also in the GSH and Cp levels.

In contrast, the MDA level in cattle with cutaneous papilloma was significantly higher than in the healthy cattle. MDA is a recognized as a lipid peroxidation marker and excessive MDA production has been associated with different pathological states $[3,9]$. It is clear that lipid peroxidation is involved in cancer aetiology. Therefore, the MDA level is a potential initiator of cancer, as well as being a biomarker of lipid peroxidation [9]. High MDA levels have been detected in skin cancers such as basal cell carcinoma and non-melanoma skin carcinoma tissue exposed to UV [13]. Antioxidant imbalance plays a pivotal role in the pathogenesis of skin diseases. The results of the present study may indicate that immunodeficiency is causing inadequate antioxidation of the skin and as a consequence, cutaneous papillomatosis.

\section{CONCLUSIONS}

In conclusion, the important role of Se in skin diseases was reinforced by this study. In addition, new data were generated for the possible roles of $\mathrm{Si}$ and $\mathrm{Ni}$ in the genesis of cancer, including cutaneous papillomatosis in cattle. Furthermore, MDA may be a more sensitive indicator of cutaneous papilloma in cattle than SOD, CAT and Cp. Further investigations of the molecular mechanisms and the identification of distinct oxygen species involved in cutaneous papillomatosis are necessary.

\section{MANUFACTURER \\ ${ }^{1}$ Thermo Fisher Scientific. Waltham, MA, USA.}

Acknowledgements. The authors thank Gregory T. Sullivan of the University of Queensland for editing the English in an earlier version of this manuscript.

Ethical approval. All procedures, treatments and animal care were in compliance with the international and Turkish guidelines for the care and use of animals. The study design was approved by The Local Ethical Committee for Animal Experiments of Ondokuz Mayis University (No:2017/27).

Declaration of interest. The authors report no conflicts of interest. The authors alone are responsible for the content and writing of paper.

\section{REFERENCES}

1 Aebi H. 1974. Catalase. In: Bergmeyer H.U. (Ed). Methods of Enzymatic Analysis. New York: Academic Press Inc, pp. 673-677.

2 Alaejos M.S., Romero D.F.J. \& Romero D. 2000. Selenium and cancer: some nutritional aspects. Nutrition. 16(5): 376-383.

3 Ayala A., Munoz M.F. \& Arguelles S. 2014. Lipid peroxidation: production, metabolism, and signalling mechanisms of malondialdehyde and 4-hydroxy-2-nonenal. Oxidative Medicine and Cellular Longevity. 2014: 360438.

4 Baudoin C., Charveron M., Tarroux R. \& Gall Y. 2002. Environmental pollutants and skin cancer. Cell Biology and Toxicology. 18: 341-348.

5 Beutler E., Duran O. \& Kelley B.M. 1963. Improved method for determination of blood glutathione. Journal of Laboratory and Clinical Medicine. 28: 882-888.

6 Bickers D.R. \& Athar M. 2006. Oxidative stress in the pathogenesis of skin disease. Journal of Investigative Dermatology. 126(12): 2565-2575.

7 Bofetta P. 1993. Carcinogenicity of trace elements with reference to evaluations made by the International Agency for Research on Cancer. Scandinavian Journal of Work, Environment \& Health. 19(Suppl 1): 67-70. 
8 Corah L. 1996. Trace mineral requirements of grazing cattle. Animal Feed Science and Technology. 59(1-3): 61-70.

9 Del Rio D., Stewart A.J. \& Pellegrini N. 2005. A review of recent studies on malondialdehyde as toxic molecule and biological marker of oxidative stress. Nutrition, Metabolism \& Cardiovascular Diseases. 15(4): 316-328.

10 Hatama S. 2012. Cutaneous papillomatosis in cattle. Journal of Disaster Research. 7(3): 319-323.

11 Ip C. 1998. Lessons from basic research in selenium and cancer prevention. The Journal of Nutrition. 128: 1845-1854.

12 Jelinek F. \& Tachezy R. 2005. Cutaneous papillomatosis in cattle. Journal of Comparative Pathology. 132(1): 70-81.

13 Majidi Z., Djalali M., Javanbakht M.H., Fathi M., Zarei M. \& Foladsaz K. 2017. Evaluation of the level of zinc and malondialdehyde in basal cell carcinoma. Iranian Journal of Public Health. 46(8): 1104-1109.

14 Mayland H.F. \& Shewmaker G.E. 2001. Animal health problems caused by silicon and other mineral imbalances. Journal of Range Management. 54(4): 441-446.

15 Nakahori R., Takahashi R., Akashi M., Tsutsui K., Harada S., Matsubayashi R., Nakagawa S., Momosaki S. \& Akagi Y. 2015. Breast carcinoma originating from a silicone granuloma: a case report. World Journal of Surgical Oncology. 13: 72.

16 Navarro Silvera S.A. \& Rohan T.E. 2007. Trace elements and cancer risk: A review of the epidemiologic evidence. Cancer Causes and Control. 18(1): 7-27.

17 Parantainen J., Tenhunen E., Kangasniemi R., Sankari S. \& Atroshi F. 1987. Milk and blood levels of silicon and selenium status in bovine mastitis. Veterinary Research Communications. 11: 467-477.

18 Prasad S., Gupta S.C. \& Tyagi A.K. 2017. Reactive oxygen species (ROS) and cancer: Role of antioxidative nutra ceuticals. Cancer Letters. 387: 95-105.

19 Ravin H.A. 1961. An improved colorimetric enzymatic assay of ceruloplasmin. The Journal of Laboratory and Clinical Medicine. 58: 161-168.

20 Ray P.D., Huang B.W. \& Tsuji Y. 2012. Reactive oxygen species (ROS) homeostasis and redox regulation in cellular signalling. Cellular Signalling. 24(5): 981-990.

21 Rayman M.P. 2000. The importance of selenium to human health. Lancet. 356(9225): 233-241.

22 Salib F.A. \& Farghali H.A. 2011. Clinical, epidemiological and therapeutic studies on Bovine Papillomatosis in Northern Oases, Egypt in 2008. Veterinary World. 4(2): 53-59.

23 Schwartz M.K. 1975. Role of trace elements in cancer. Cancer Research. 35: 3481-3487.

24 Trouba K.J., Hamadeh H.K., Amin R.P. \& Germolec D.R. 2002. Oxidative stress and its role in skin disease. Antioxidants \& Redox Signaling. 4(4): 665-673.

25 Willett W.C., Morris J.S., Pressel S., Taylor J.O., Polk B.F., Stampfer M.J., Rosner B., Schneider K. \& Hames C.G. 1983. Prediagnostic serum selenium and risk of cancer. Lancet. 322(8342): 130-134.

26 Yoshioka T., Kawada K., Shimada T. \& Mori M. 1979. Lipid peroxidation in maternal and cord blood and protective mechanism against activated-oxygen toxicity in the blood. American Journal of Obstetrics and Gynecology. 135: 372-376.

27 Zeng H. \& Combs G.F. 2008. Selenium as an anticancer nutrient: roles in cell proliferation and tumor cell invasion. The Journal of Nutritional Biochemistry. 19(1): 1-7. 